\title{
ADESÃO AO TRATAMENTO DE USUÁRIOS DE UM CAPS AD DO INTERIOR DA BAHIA
}

\author{
Iandra Sara dos Santos Ferreira ${ }^{1}$; Sinara de Lima Souza ${ }^{2}$ \\ 1. Bolsista PEVIC, Graduando em Enfermagem, Universidade Estadual de Feira de Santana, e-mail: \\ iandra.sara4@gmail.com \\ 2. Orientador, Departamento de Saúde, Universidade Estadual de Feira de Santana, e-mail: sinarals@uefs.br
}

PALAVRAS-CHAVE: adesão; caps; drogas.

\section{INTRODUÇÃO}

As substâncias psicoativas (SPAs) são conhecidas pelo homem desde seus primórdios, e em tempos mais modernos, com as tecnologias que possibilitam o tráfego instantâneo da informação, um número cada vez maior de pessoas tem acesso ao conhecimento sobre drogas lícitas e ilícitas (GIGLIOTTI E GUIMARÃES, 2010). A relação estabelecida entre os indivíduos e as SPAs, tem sido plano de fundo para o surgimento ou exacerbação de problemas sociais, econômicos e de saúde.

Respaldado pela Reforma Psiquiátrica na década de 80, foram criados os Centros de Atenção Psicossocial (CAPS) (VIDAL, BANDEIRA E GONTIJO, 2007). O CAPS ad é destinado a assistência de usuários de drogas, sejam elas lícitas ou ilícitas, e adota as estratégias de redução de danos como ferramenta das ações de prevenção e promoção da saúde.

$\mathrm{Na}$ condição de estudante do curso de graduação em Enfermagem, saliento a importância de analisar a percepção dos usuários do CAPS ad sobre a adesão aos serviços terapêuticos oferecidos pela sua relevância para uma prática exitosa. Diante disto surgiu o seguinte questionamento: Qual a percepção dos usuários de um CAPS ad do interior da Bahia sobre a adesão aos serviços terapêuticos oferecidos?

Nesta perspectiva este estudo teve como objetivo analisar a percepção dos usuários do CAPS ad sobre a adesão aos serviços terapêuticos oferecidos por um CAPS ad do interior da Bahia.

\section{METODOLOGIA}

Trata-se de um estudo qualitativo, descritivo. O campo do estudo foi um CAPS ad do interior da Bahia. A técnicas de coleta adotada nesse estudo foi a entrevista semiestruturada. Os participantes foram os usuários do CAPS ad. Os dados dessa pesquisa são oriundos do banco de dados do projeto de pesquisa e extensão aprovado pela resolução CONSEPE N. ${ }^{\text {o }}$ 43/2012 intitulado "Perfil sociodemográfico e aspectos relacionados à adesão ao tratamento de pacientes de um CAPS ad do interior da Bahia", com o intuito de apreender o fenômeno na sua dinâmica. Ou seja, a adesão dos usuários do CAPS ad ao tratamento e os fatores que influenciam nessa decisão.

Análise de dados foi através da análise de conteúdo, na qual foram seguidas as etapas sugeridas por Gomes (2007, p100): transcrição das entrevistas, leitura compreensiva do material selecionado, exploração do material, elaboração e síntese interpretativa. A partir desse processo, chegamos à categorização dos dados, a fim de realizar a interpretação propriamente dita dos achados do estudo.

No tocante aos critérios éticos a serem observados nas pesquisas envolvendo seres humanos, foram adotadas as recomendações da Resolução no 466/2012 do Conselho Nacional de Saúde (BRASIL, 2012) .O projeto foi submetido à apreciação do Comitê de Ética e Pesquisa da Universidade Estadual de Feira de Santana- BA, tendo sido registrado e aprovado sob o protocolo n. ${ }^{\circ} 114 / 2011$ (CAAE ${ }^{\circ}$ 0119.059.000-11). 


\section{RESULTADOS E/OU DISCUSSÃO}

\section{Caracterização dos participantes do estudo}

Participaram da pesquisa 8 usuários com a faixa etária entre 29 e 62 anos. No tocante ao sexo, três eram do sexo masculino e cinco do sexo feminino.

\begin{tabular}{lll} 
Tabela 1. Faixa etária dos participantes do estudo & Quantitativo \\
\hline Idade & 0 & 0 \\
$14-25$ & 2 & 25 \\
$26-35$ & 2 & 37,5 \\
$36-45$ & 3 & 12,5 \\
$46-55$ & 1 & $\mathbf{1 0 0}$ \\
$56-65$ & $\mathbf{8}$ & \\
Total & & \\
\hline
\end{tabular}

Fonte: Banco de dados da pesquisa.

Aderir ao tratamento constitui-se como um fator imprescindível para o processo de reabilitação. Monteiro et al.(2011) consideram a adesão quando o cliente permanece acima de três meses em tratamento, podendo ter alta a partir do terceiro mês a depender da situação.

O nosso estudo apresenta uma faixa etária entre 26-65 anos com o tempo de adesão ao tratamento mais elevado. Dois usuários estão em tratamento por 2 e 5 meses, sucessivamente, um usuário está sendo acompanhado há 1 ano, e os demais, estão no serviço por um período entre 2 e 6 anos.

Contextualizando as categorias

Á partir da organização e análise do material emergiram quatro categorias, sendo elas: adesão depende da força de vontade; influência da medicação prescrita; relação entre trabalhadores e usuários e a recaída enquanto possibilidade.

\section{Adesão depende da força de vontade}

No estudo, a força de vontade se revelou pela importância destacada pelos participantes em relação ao autoconhecimento do usuário a respeito das suas necessidades.

[...] quando tem vontade própria tudo, às vezes, fica mais fácil e o cigarro para mim é uma droga como se fosse qualquer outra. E6

Em seus estudos, Ferreira et al.(2015) ao trabalhar com o modelo transteórico de mudança comportamental, revela que o estágio de ação inclui o momento em que o indivíduo sente a necessidade de uma ajuda mais direcionada e por isso busca o tratamento por vontade própria. Também refere que o tratamento iniciado sob medidas coercitivas, apresenta limitações possivelmente pela falta de motivação, o que resulta na baixa adesão.

\section{Influência de medicação prescrita}

Em alguns casos a medicação foi o motivo pelo qual o usuário teve o primeiro contato com o serviço. Uma outra situação a suposta ineficácia do remédio e a falta de vontade em tomar a medicação dificultou na adesão.

[...] porque eu tinha dificuldade para consegui os remédios, né? Era aquela coisa no posto. Então a médica teve uma pena de mim e me encaminhou[...] os remédios, e para mim foi ótimo [...] E1

Ferreira et al.(2015) relata que o uso de medicação é um fator que influencia na adesão ao tratamento, visto que, muitos usuários tem a ideia que somente usando o medicamento será possível a reabilitação. A medicação se constitui em componente importante no tratamento. Porém, deve estar associado as outras modalidades terapêuticas presentes no CAPS ad.

\section{Relação entre trabalhadores e usuários}

Quando nos reportamos à humanização do cuidado, compreendemos que esta se dá no âmbito das relações. Sendo assim, a relação estabelecida entre os trabalhadores e usuários, se 
constituem em componente fundamental para que ocorra a adesão ao tratamento, consequente do acolhimento e vínculos estabelecidos.

[...] quando cheguei aqui também fui atendida diretamente, não teve demora [...] Foi ótimo mesmo. Tenho um acompanhamento do artesanato, o de memória. Então pra mim ajudou muito. E1

[...] eu gostei, eu amei mesmo, aqui os meninos são maravilhosos. E2

Estas falas demonstram afinidade entre a equipe e os usuários. Pudemos inferir que entre os mesmos tem se estabelecido uma relação de empatia. Tratando desta questão, Mielke et al.(2011) consideram que para o desenvolvimento das práticas de reabilitação, é necessário utilizar aspectos relacionais e dialógicos que envolve o acolhimento, a escuta e o vínculo. Ainda ao que compete ao vínculo Ferreira et al.(2015 ) trazem, que sem vínculo os pacientes não aderem ao tratamento e não retornam ao serviço.

Fonseca et al.(2014) destacam que uma equipe profissional bem habilitada aliada as atividades propostas pelo tratamento constituem-se como elementos primordiais para adesão ao tratamento e consequentemente, a efetividade dos usuários.

\section{A recaída enquanto possibilidade}

A recaída no contexto da dependência química, a depender da perspectiva do usuário e equipe de saúde, pode ser vista como um sinal de fraqueza ou fracasso terapêutico, ou ainda como um deslize a ser superado. Em se tratando do CAPS ad, que atua a partir da lógica de redução de danos, a abstinência é tida como uma possibilidade, assim como a recaída.

[...] muitas vezes o vício é mais forte que a força de vontade. E2

[...] os remédios daqui eu parei, mas depois... eu fui mais fraca do que... a própria vontade né? Mas eu parei, umas 3 ou 4 vezes. E5

Os relatos acima apontam para a visualização do vício e da relação do mesmo com fraqueza da pessoa na continuidade do tratamento. Porém, faz-se necessário compreender em qual contexto esse sentimento de fraqueza emergiu.

Marques e Seibel (2000) discutindo sobre craving ou "fissura" o descrevem como um estado pelo qual o individuo tem a extrema necessidade, ou desejo intenso do uso da droga que pode ocorrer momentos após o uso, ou após períodos prolongados sem a droga, em abstinência. Ainda na perspectiva do craving ou "fissura" discorrem que, a rede sociorrelacional e o ambiente são motivações que podem desencadear a mudança de comportamento e consequentemente o contato com a droga.

\section{CONSIDERAÇÕES FINAIS}

O estudo realizado revelou que a força de vontade foi percebida pelos participantes como um elemento essencial para a adesão ao tratamento, e também, para melhor resolubilidade da terapêutica proposta. $\mathrm{O}$ uso da medicação foi apontado como facilitador para a adesão, contudo, foi compreendido que nem só por meio dela é possível a reabilitação. Por esse motivo as outras modalidades de tratamento oferecidas pelo CAPS ad, assim como o acolhimento e o estabelecimento de vínculo entre trabalhadores e usuários, se configuraram como importantes elementos para a adesão. A ocorrência da recaída surgiu enquanto possibilidade no processo terapêutico, em que o contexto de relações interpessoais, o ambiente ao qual o usuário estava inserido e a sua relação com a droga, se constituíram como definidores de maior ou menor vulnerabilidade para a sua ocorrência.

Consideramos que os objetivos propostos foram alcançados. Como sugestão para pesquisas futuras, sinalizamos para a possibilidade da realização de um projeto de intervenção, no qual sejam realizadas oficinas de sensibilização da equipe para o acolhimento, vínculo e responsabilização, na perspectiva de propiciar a adesão ao projeto terapêutico singular pelos usuários do CAPS ad. 


\section{REFERÊNCIAS}

BRASIL. MINISTÉRIO DA SAÚDE. Resolução no 466 de 12 de dezembro de 2012 do Conselho Nacional de Saúde. Brasília, DF: Ministério da Saúde, 2012.

GILIOTTI, Analice; GUIMARÃES, Angela. Diretrizes gerais para o tratamento da dependência química. Rio de Janeiro: Rubio, 2010.

VIDAL, Carlos Eduardo Leal; BANDEIRA, Marina; GONTIJO, Eliane Dias. Reforma psiquiátrica e serviços residenciais terapêuticos. J. Bras. Psiquiatr., Rio de Janeiro, v. 57, n $1,2008$.

GOMES, R. Análise e interpretação de dados em pesquisa qualitativa. In: MINAYO, M. C. S. (Org.). Pesquisa social: teoria, método e criatividade. 25. ed. revista e atualizada. Petrópolis: Vozes, 2007. p. 79-108.

MARQUES, A. C., SEIBEL, S. D. O Craving. In: SEIBEL, S. D; TOSCANO Jr., A. Dependência de Drogas. São Paulo: Atheneu, 2000, 239-246.

FERREIRA, Aline Cristina Zerwes et al. Fatores que interferem na adesão ao tratamento de dependência química: percepção de profissionais de saúde. Revista Mineira de Enfermagem. v.19, n, 2, p. 150-156, abr/jun. 2015.

FONSECA, Rayde Luiz, et al. Percepção de usuários de crack sobre o tratamento em um centro de atenção psicossocial, álcool e outras drogas. Rev. APS. v.17, n. 2, p. 214-222, abr/jun. 2014.

MONTEIRO, Claudete Ferreira de Souza et al. Perfil sociodemográfico e adesão ao tratamento de dependentes de álcool em CAPS-ad do Piauí. Esc. Anna Nery. v.15, n.1, pp.90-95. 2011

MIELKE, Fernanda Barreto et al . Características do cuidado em saúde mental em um CAPS na perspectiva dos profissionais. Trab. educ. saúde, Rio de Janeiro, v. 9, n. 2, p. 265-276, Oct. 2011. 